\title{
CT imaging-based approaches to cochlear duct length estimation-a human temporal bone study
}

\author{
Tabita Breitsprecher ${ }^{1} \cdot$ Anandhan Dhanasingh ${ }^{2} \cdot$ Marko Schulze $^{3} \cdot$ Markus Kipp $^{3} \cdot$ Rami Abu Dakah ${ }^{4}$. \\ Tobias Oberhoffner $^{1} \cdot$ Michael Dau $^{5} \cdot$ Bernhard Frerich $^{5} \cdot$ Marc-André Weber $^{6} \cdot$ Soenke Langner $^{6} \cdot$ Robert Mlynski $^{1}$. \\ Nora M. Weiss ${ }^{1}$ (i)
}

Received: 11 March 2021 / Revised: 18 June 2021 / Accepted: 30 June 2021 / Published online: 31 August 2021

(C) The Author(s) 2021

\begin{abstract}
Objectives Knowledge about cochlear duct length (CDL) may assist electrode choice in cochlear implantation (CI). However, no gold standard for clinical applicable estimation of CDL exists. The aim of this study is (1) to determine the most reliable radiological imaging method and imaging processing software for measuring CDL from clinical routine imaging and (2) to accurately predict the insertion depth of the CI electrode.

Methods Twenty human temporal bones were examined using different sectional imaging techniques (high-resolution computed tomography $[\mathrm{HRCT}]$ and cone beam computed tomography [CBCT]). CDL was measured using three methods: length estimation using (1) a dedicated preclinical 3D reconstruction software, (2) the established A-value method, and (3) a clinically approved otosurgical planning software. Temporal bones were implanted with a $31.5-\mathrm{mm}$ CI electrode and measurements were compared to a reference based on the CI electrode insertion angle measured by radiographs in Stenvers projection $\left(\mathrm{CDL}_{\text {reference }}\right)$. Results A mean cochlear coverage of 74\% (SD 7.4\%) was found. The $\mathrm{CDL}_{\text {reference }}$ showed significant differences to each other method $(p<0.001)$. The strongest correlation to the $\mathrm{CDL}_{\text {reference }}$ was found for the otosurgical planning software-based method obtained from HRCT $\left(\mathrm{CDL}_{\mathrm{SW}-\mathrm{HRCT}} ; r=0.87, p<0.001\right)$ and from CBCT $\left(\mathrm{CDL}_{\mathrm{SW}-\mathrm{CBCT}} ; r=0.76, p<0.001\right)$. Overall, $\mathrm{CDL}$ was underestimated by each applied method. The inter-rater reliability was fair for the CDL estimation based on 3D reconstruction from CBCT $\left(\mathrm{CDL}_{3 \mathrm{D}-\mathrm{CBCT}}\right.$; intra-class correlation coefficient $\left.[\mathrm{ICC}]=0.43\right)$, good for $\mathrm{CDL}$ estimation based on 3D reconstruction from HRCT ( $\mathrm{CDL}_{3 \mathrm{D}-\mathrm{HRCT}}$; ICC $\left.=0.71\right)$, poor for CDL estimation based on the A-value method from HRCT $\left(\mathrm{CDL}_{\mathrm{A}-\mathrm{HRCT}}\right.$; ICC $=$ 0.29), and excellent for CDL estimation based on the A-value method from $C B C T\left(C D L_{A-C B C T} ; I C C=0.87\right)$ as well as for the $\mathrm{CDL}_{\mathrm{SW}-\mathrm{HRCT}}(\mathrm{ICC}=0.94), \mathrm{CDL}_{\mathrm{SW}-\mathrm{CBCT}}(\mathrm{ICC}=0.94)$ and $\mathrm{CDL}_{\text {reference }}(\mathrm{ICC}=0.87)$.

Conclusions All approaches would have led to an electrode choice of rather too short electrodes. Concerning treatment decisions based on CDL measurements, the otosurgical planning software-based method has to be recommended. The best inter-rater reliability was found for $\mathrm{CDL}_{\mathrm{A}-\mathrm{CBCT}}$, for $\mathrm{CDL}_{\mathrm{SW}-\mathrm{HRCT}}$, for $\mathrm{CDL}_{\mathrm{SW}-\mathrm{CBCT}}$, and for $\mathrm{CDL}_{\text {reference. }}$.

Key Points

- Clinically applicable calculations using high-resolution CT and cone beam CT underestimate the cochlear size.

- Ten percent of cochlear duct length need to be added to current calculations in order to predict the postoperative CI electrode position.

- The clinically approved otosurgical planning software-based method software is the most suitable to estimate the cochlear duct length and shows an excellent inter-rater reliability.
\end{abstract}

Keywords Cochlea $\cdot$ Acoustic stimulation $\cdot$ Imaging, three-dimensional $\cdot$ Electrodes, implanted

Nora M. Weiss

hno@med.uni-rostock.de

1 Department of Otorhinolaryngology, Head and Neck Surgery „Otto Körner“, Rostock University Medical Center, Doberaner Strasse 137-139, D-18057 Rostock, Germany

2 MED-EL, Fürstenweg 77a, A-6020 Innsbruck, Austria

3 Rostock University Medical Center, Institute of Anatomy, Gertrudenstrasse 9, Rostock, Germany

Springer
4 Rostock University, 18051 Rostock, Germany

5 Department of Oral, Maxillofacial and Facial Plastic Surgery, Rostock University Medical Center, Schillingallee 35, D-18057 Rostock, Germany

6 Department of Radiology, Rostock University Medical Center, Schillingallee 35, D-18057 Rostock, Germany 


$\begin{array}{ll}\text { Abbreviations } & \\ \text { ANOVA } & \text { One-way analysis of variance } \\ \text { CBCT } & \text { Cone beam computed tomography } \\ \mathrm{CC} & \text { Cochlear coverage } \\ \mathrm{CDL} & \text { Cochlear duct length } \\ \mathrm{CDL}_{3 \mathrm{D}} & \text { Cochlear duct length 3D reconstruction } \\ \mathrm{CDL}_{\mathrm{A}} & \text { Cochlear duct length A-value method } \\ \mathrm{CDL}_{\mathrm{CBCT}} & \text { CDL estimated from CBCT } \\ \mathrm{CDL}_{\mathrm{HRCT}} & \text { CDL estimated from HRCT } \\ \mathrm{CDL}_{\text {reference }} & \text { Cochlear duct length reference } \\ \mathrm{CDL}_{\mathrm{SW}} & \text { Cochlear duct length software-based method } \\ \mathrm{CI} & \text { Cochlear implant } \\ \text { FOV } & \text { Field of view } \\ \mathrm{HRCT} & \text { High-resolution computed tomography } \\ \mathrm{HU} & \text { Hounsfield units } \\ \mathrm{IA} & \text { Insertion angle } \\ \text { ICC } & \text { Intra-class correlation coefficient } \\ \text { IEM } & \text { Inner ear malformation } \\ \text { LW } & \text { Lateral cochlear wall } \\ \text { pBTL } & \text { Percentage of basal turn length }\end{array}$

\section{Introduction}

The spectral information of a cochlear implant (CI) electrode resembles Greenwood's function, which matches the inner ear's hair cells and corresponding spiral ganglion neurons to the stimulation frequency [1]. This knowledge may contribute to optimize fitting strategies and the representation of spectral information to the auditory pathway. Variations in size and shape of the cochlea can affect the CI electrode position as well as the cochlear coverage (CC) and consequently the final pitch discrimination [2-13]. In cases of surgery under the aim of residual hearing preservation, an individual choice of electrode length is favorable and several proposals to approach the appropriate electrode length depending on the cochlear duct length $(\mathrm{CDL})$ are made $[3,14]$. The best speech perception is reported in a CC between 70 and 75\% [15]. This is in line with earlier studies that could not find a benefit from very deep insertion $[16,17]$. A too short electrode insertion may lead to poorer functional outcomes [18]. When determining the $\mathrm{CC}$ for an optimal stimulation by a CI, it is important to understand the individual effects of the cochlear geometry on the choice of different electrode lengths. There are suggestions to adapt the electrode to the individual length of the cochlea under the aim of structure preservation for acoustic stimulation with hearing aids and optimized compensation of the profound hearing loss by electrical stimulation [19]. For this purpose, the dimensions of the cochlea may be measured using routine radiological imaging of the temporal bone. In advance to CI surgery, high-resolution computed tomography (HRCT) or cone beam computed tomography (CBCT) of the temporal bone is performed in clinical routine, offering the opportunity of analysis of the individual surgical site [20]. There are several approaches to estimate the CDL, mostly using volume-generated methods based on HRCT and magnetic resonance imaging (MRI) [21-24]. The CDL appears to be an important factor affecting CI outcomes and encouraging research to establish strategies for electrode selection [25]. However, it is unknown whether these methods are suitable for a reliable assessment of fine structured cochlear dimensions. In the experimental setting, synchrotron imaging is considered the most accurate imaging modality, but cannot be applied in clinical routine [26]. For CDL estimation from clinical imaging and selecting a suitable CI electrode, the spline curve method is assumed to lead to the most suitable results [23]. Nevertheless, reliable methods to perform CDL measurements are still demanded [24].

The goal of the present study is to determine (i) the most reliable radiological imaging and imaging software for measuring cochlear dimensions in clinical routine and (ii) which method is suitable to accurately predict the actual insertion depth of the CI electrode in order to provide patients with optimal conditions for combined cochlear stimulation with hearing aids and $\mathrm{CI}$.

\section{Methods}

The study protocol was approved by the local Ethics Committee in accordance with the Helsinki declaration (registration number: A2019-0089). Fresh temporal bones used in this study originated from the university donor program at the local Institute of Anatomy. All patients registered voluntarily to donate their body for medical scientific research and gave written informed consent during lifetime.

A total of 20 fresh human temporal bones were examined using two different cross-sectional imaging techniques used in clinical diagnostic workup before CI surgery, i.e., HRCT and CBCT. HRCT examinations were performed using a 64-row multidetector CT (Aquilion, Canon Medical Systems) with $0.5-\mathrm{mm}$ collimation $(120 \mathrm{kVP}, 150 \mathrm{mAs})$ and a $512 \times 512$ matrix. Images were reconstructed using a bone kernel (slice thickness: $0.2 \mathrm{~mm}$ ). CBCT examinations were performed using a Pax-Zenith 3D (VATECH Co. Ltd.; capture software: byzz, version 5.8.3, Orangedental). The temporal bone was positioned analogous to the patient's upright position in CBCT. The field of view (FOV) was set to $9 \times 12 \mathrm{~cm}$; the voxel size was $0.2 \mathrm{~mm}$.

Based on these imaging data, cochlear parameters were measured using three different software-based methods: (1) length estimation based on a highly detailed 3D reconstruction of the cochlea using special 3D software (Materialise Mimics, version 21.0, Materialise NV), (2) length estimation based on the established A-value method, and (3) length 

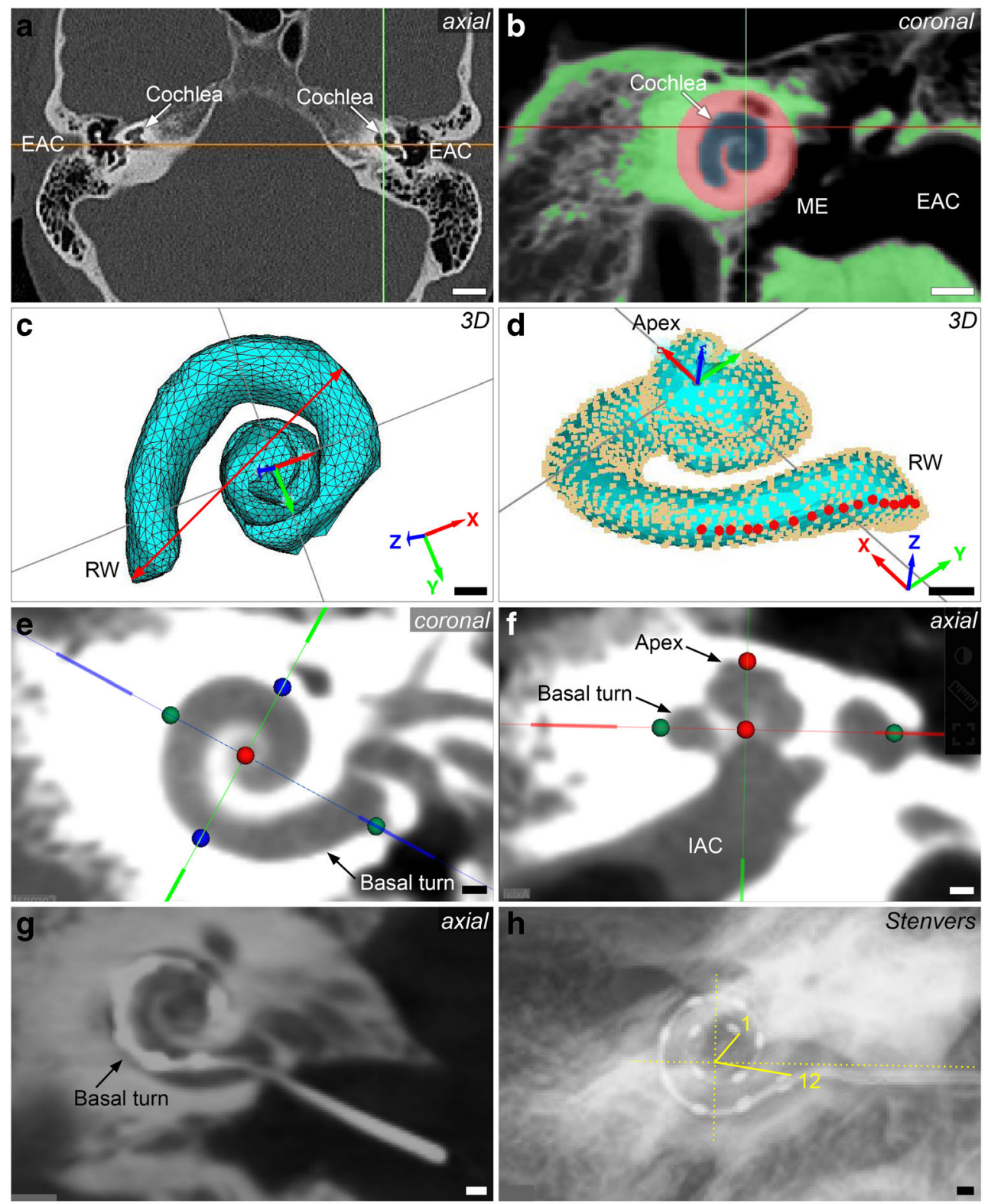

Fig. 1 Cochlear duct length (CDL) measurement approaches. a Axial view of a high-resolution computed tomography (HRCT) scan in Materialise Mimics software. b Segmentation of a cone beam computed tomography (CBCT) scan in Materialise Mimics, threshold mask (green), region A (blue, cochlear fluid), and region $\mathrm{B}$ (red, otic capsule). c 3D model of the cochlea after segmentation. Red double arrow, measurement of the A-value from the round window (RW) to the opposite lateral wall (LW). Alignment: $\mathrm{z}$-axis (blue), $\mathrm{x}$-axis (red), $\mathrm{y}$-axis (green) with $\mathrm{z}$-axis pointing through the modiolus and the basal turn positioned in the $x y-$ level. d Spline curve reconstruction from cloud point surface of the 3D model. Red dots: selected points on the LW. Alignment: $\mathrm{z}$-axis (blue), $\mathrm{x}$ axis (red) $y$-axis (green) with $z$-axis pointing through the modiolus and the basal turn positioned in the xy-level. e CBCT scan with view on the

cochlea in the oblique coronal view in the otosurgical planning software, with measurements of the A-value (cochlear diameter; green dots) and the B-value (cochlear width; blue dots). f CBCT scan, with view on the cochlea in the axial view in the otosurgical planning software, red dots: determination of the height of the cochlea. g Postinsertion CBCT scan with view on the cochlea in the oblique coronal view in the otosurgical planning software showing the fully inserted electrode in the basal turn. $\mathbf{h}$ Postinsertion radiograph (Stenvers projection) showing the measurement of the insertion angle determined between the first (1.) and the twelfth (12.) electrodes. Yellow lines, angle of the first/twelfth electrode. EAC, external ear canal; IAC, internal auditory canal; ME, middle ear; $\mathrm{RW}$, round window. Scale bars: $10 \mathrm{~mm}(\mathbf{a}, \mathbf{b}), 1 \mathrm{~mm}(\mathbf{c}-\mathbf{h})$

estimation based on a recently introduced clinically approved otosurgical planning software based on a combination of A-value and B-value methods (Otoplan, version 3.0, Cascination) (Fig. 1).

\section{D segmentation}

3D segmentation was performed using threshold analysis and a 3D model of the cochlea was reconstructed with 
Materialise Mimics Innovation Suite (version 21.0, Materialise NV). Analysis was based on the density of the fluid within the membranous labyrinth. The range was set to -1024 to +280 Hounsfield units (HU) for HRCT. The threshold ranges were set separately for each modality and had to be modified since tissue density in CBCT is usually specified in gray scale, not in HU [27]. The round window was marked as the starting point for the spline curve measurements. The cochlea was segmented manually in each slice by selecting the cochlear fluid spaces ("region $\mathrm{A}$ "), and the adjoining bony region, the otic capsule ("region B") (Fig. 1B). A 3D model was created semi-automatically by the software. The lateral cochlear wall (LW) and A-value were measured using the Computer Simulation Technology Software (CST studio suite, Simulia, Dassault Systèmes) (Fig. 1C). A spline curve of the LW was created manually from the softwarebased point cloud model (Fig. 1D). To enable a full view onto the basal turn of the cochlea for later A-value determination, the $3 \mathrm{D}$ model was projected into a Cartesian coordinate system with the z-axis representing the modiolus (Fig. 1 C,D).

\section{A-value method}

Escudé et al developed a formula to calculate the CDL based on the basal turn as pictured in HRCT images and the insertion angle (IA) $\theta$ of the CI electrode [11].

The A-value describes the distance between the round window and the opposite LW passing through the modiolus. To estimate the full CDL, $\theta$ is set to $900^{\circ}$ imitating a CC of $100 \%$ and representing two and a half turns of the cochlea. The CDL is calculated as follows:

$\mathrm{LW}=2.62 \times \mathrm{A} \times \log _{\mathrm{e}}\left(1+\frac{\theta}{235}\right)$

$\mathrm{LW}=2.62 \times \mathrm{A} \times 1.57$

\section{Otosurgical planning software-based method}

Otoplan (Cascination AG) was used as otosurgical planning software. The software requires the user to provide defined anatomical landmarks capturing the diameter (A-value) and width (B-value: cochlear width perpendicular to the line segment of the A-value, intersection point modiolus) of the cochlea basal turn in the oblique coronal view which is obtained by rotating the axial, coronal, and sagittal axis until the basal turn is fully captured. A third parameter (H-value) defines the height of the cochlea between the apex and the base of the cochlea through the modiolus perpendicular to the A and $\mathrm{B}$ lines. The CDL calculation is based on the elliptic circular approximation and percentage of basal turn length (pBTL) as reported by Schurzig et al. [37].

$\mathrm{CDL}_{\mathrm{LW}}=\operatorname{pBTL}(\theta)$

$\times[1.18 \times(\mathrm{A}-0.7)+2.69 \times(\mathrm{B}-0.7)-\sqrt{0.72 \times(\mathrm{A}-0.7) \times(\mathrm{B}-0.7)}]$

The software automatically estimates the CDL along the organ of Corti using a multiplication factor of 0.9 [27].

As an additional approximation to $C D L$ values from higher imaging resolutions, a further estimation of the CDL was calculated mathematically by multiplying the CDL values by $10 / 9\left(\mathrm{CDL}_{10 / 9}\right)$ based on the findings of Schurzig et al who found CDL values approximately $10 \%$ larger, when segmented from high-resolution $\mu \mathrm{CT}$ images [23].

Additionally, the predicted $\mathrm{CC}$ and the predicted IA from the different imaging modalities were calculated as follows:

$\mathrm{CC}(\%)=\frac{31.5 \mathrm{~mm}}{\mathrm{CDL}(\mathrm{mm})} \times 100 \%$.

$\mathrm{IA}\left({ }^{\circ}\right)=\frac{\mathrm{CC}(\%) \times 900^{\circ}}{100 \%}$

and compared to the reference.

All temporal bones were implanted with a CI electrode (MED-EL Flex soft electrode array, $31.5 \mathrm{~mm}$, MED-EL $\mathrm{GmbH}$ ) by a single surgeon (NMW). The electrode array was inserted using a posterior tympanotomy and round window approach.

Full insertion and correct scalar position were proven by postinsertion CBCT in all cases (Fig. 1G). The insertion depth and intracochlear position were verified by postoperative radiological imaging (Stenvers projection, Fig. 1H). The IA was measured using the method of Xu et al [5].

As a reference, the CDL was estimated based on the CI electrode insertion angle measured by radiographs in Stenvers projection $\left(\mathrm{CDL}_{\text {reference }}\right)$ according to the following formula presuming a cochlear angle of $900^{\circ}$ :

$\mathrm{CDL}(\mathrm{mm})=\frac{31.5 \mathrm{~mm}}{\mathrm{IA}\left({ }^{\circ}\right)} \times 900^{\circ}$.

All measurements were performed by two independent examiners. One investigator (Ear, Nose and Throat [ENT] resident with 1 year of experience interpreting temporal bone imaging) performed all measurements after an instruction and training period under the supervision of two senior physicians (radiology consultant and ENT consultant, each with more than 6 years of experience). The second investigator was chosen according to the grade of experience in the use of each 
individual method (3D segmentation and A-value method: engineer with more than 5 years' experience in the use of Materialise Mimics and 3D reconstructions from medical imaging; otosurgical planning software-based method and insertion angle determination: scientist specialized in otologic research with expertise of more than 4 years in the interpretation of temporal bone imaging). Only the measurements performed by the same person (ENT resident) were used for further analyses. Both investigators were blinded to the previous measurement. Consistency of the measurements was tested by determining the inter-rater reliability.

\section{Statistical analysis}

All statistical tests were selected before data collection. Statistical analyses were performed using Microsoft Excel (version 15.29, Microsoft Corporation) and Prism (version 8, GraphPad software). The significance level was set to $p<$ 0.05 . The assumption of normality was tested graphically using quantile-quantile plots. Data are presented as mean with standard deviation (SD) as well as absolute numbers with percentages. To compare means of the CDL between the measurement methods, a one-way analysis of variance (ANOVA) and Dunnett's test were used to correct for multiple comparisons. To compare the CDL estimations obtained from the different measurement methods and $\mathrm{CDL}_{\text {reference }}$, Pearson's correlation coefficient (PCC) was calculated. Furthermore, PCC was calculated between the $\mathrm{CDL}_{\mathrm{Sw}}$ and the A-value, $\mathrm{B}$-value, and $\mathrm{H}$-value. The agreement between the raters was determined by calculating the intra-class correlation coefficient (ICC).

\section{Results}

A total number of 20 temporal bones was investigated. The means and standard deviations of the CDL depending on the different imaging modalities and measurement techniques as well as the calculated $\mathrm{CC}$ and the calculated IA from the different imaging modalities compared to the reference are shown in Table 1. A full insertion of a $31.5-\mathrm{mm}$ electrode was achieved in all cases. No scalar dislocation and no tip fold-overs were observed. A mean $\mathrm{CC}$ of $74 \%$ was identified (SD $7.4 \%)$. The mean IA was $663^{\circ}\left(\mathrm{SD} 65.5^{\circ}\right)$.

One-way ANOVA revealed differences between the individual CDL estimation methods $(F(6,133)=25.24, p<0.001)$. Post hoc analysis showed significant differences between the $\mathrm{CDL}_{\text {reference, }}$ the $\mathrm{CDL}$ estimation based on $3 \mathrm{D}$ reconstruction from HRCT (CDL 3 D-HRCT ; mean difference $7.7 \mathrm{~mm}, 95 \% \mathrm{CI}$ 5.8-9.6 mm, $p<0.001)$, and from CBCT $\left(\mathrm{CDL}_{3 \mathrm{D}-\mathrm{CBCT}}\right.$; mean difference $6.1 \mathrm{~mm}, 95 \% \mathrm{CI} 4.2-8.0 \mathrm{~mm}, p<0.001$ ), the CDL estimation based on an otosurgical planning software from HRCT (CDL SW-HRCT $_{\text {; }}$ mean difference $6.1 \mathrm{~mm}, 95 \% \mathrm{CI}$ 4.2-8.1 $\mathrm{mm}, p<0.001)$, and from $\mathrm{CBCT}\left(\mathrm{CDL}_{\mathrm{SW}-\mathrm{CBCT}}\right.$; mean difference $5.5 \mathrm{~mm}, 95 \% \mathrm{CI} 3.6-7.5 \mathrm{~mm}, p<0.001$ ), the CDL estimation based on the A-value method from HRCT ( $\mathrm{CDL}_{\mathrm{A}-\mathrm{HRCT}}$; mean difference $7.2 \mathrm{~mm}, 95 \% \mathrm{CI} 5.3-9.1 \mathrm{~mm}, p$ $<0.001)$, and the from $\mathrm{CBCT}\left(\mathrm{CDL}_{\mathrm{A}-\mathrm{CBCT}}\right.$; mean difference 5.0 $\mathrm{mm}, 95 \%$ CI 3.1-6.9 mm, $p<0.001)$. Furthermore, differences between the $\mathrm{CDL}_{\mathrm{A}-\mathrm{HRCT}}$ and the $\mathrm{CDL}_{\mathrm{A}-\mathrm{CBCT}}$ (mean difference $2.2 \mathrm{~mm}, 95 \%$ CI $0.1-4.4 \mathrm{~mm}, p=0.04$ ) as well as between the $\mathrm{CDL}_{3 \mathrm{D}-\mathrm{HRCT}}$ and the $\mathrm{CDL}_{\mathrm{A}-\mathrm{CBCT}}$ (mean difference $2.7 \mathrm{~mm}$, 95\%CI 0.6-4.9 mm, $p=0.04$ ) were found (Fig. 2A).

When multiplying the individual values by $10 / 9$, differences between $\mathrm{CDL}_{\text {reference }}$ and $\mathrm{CDL}_{\mathrm{A}-\mathrm{CBCT}}$ as well as $\mathrm{CDL}_{\text {reference }}$ and $\mathrm{CDL}_{\mathrm{SW}-\mathrm{CBCT}}$ were no longer significant (Fig. 2B).

The correlations between the $\mathrm{CDL}_{\text {reference }}$ and the different measurement techniques are shown in Fig. 3. These correlations were significantly different between the $\mathrm{CDL}_{\mathrm{SW} \text {-HRCT }}$ and the $\mathrm{CDL}_{3 \mathrm{D}-\mathrm{HRCT}}(p=0.01)$ as well as between the $\mathrm{CDL}_{\mathrm{SW} \text {-HRCT }}$ and the $\mathrm{CDL}_{\mathrm{A}-\mathrm{HRCT}}(p=0.0007)$ and $\mathrm{CDL}_{\mathrm{A}-}$ СВСт $(p=0.01)$. Furthermore, the correlations were significantly different between the $\mathrm{CDL}_{3 \mathrm{D}-\mathrm{CBCT}}$ and the $\mathrm{CDL}_{\mathrm{A}-\mathrm{HRCT}}$ $(p=0.04)$ as well as between the $\mathrm{CDL}_{\mathrm{SW}-\mathrm{CBCT}}$ and the $\mathrm{CDL}_{\mathrm{A}-}$ HRCT $(p=0.02)$.

Measured by HRCT and estimated by the otosurgical planning software, the PCC between the A-value and the CDL was
Table 1 Means and standard deviations of the different measurement techniques for (i) the estimated cochlear duct length (CDL), (ii) the calculated cochlear coverage (CC), and (iii) the calculated insertion angle (IA) compared to the reference

\begin{tabular}{|c|c|c|c|c|c|c|c|}
\hline & \multicolumn{2}{|c|}{ 3D segmentation } & \multicolumn{2}{|c|}{ A-value method } & \multicolumn{2}{|c|}{$\begin{array}{l}\text { Otosurgical planning } \\
\text { software }\end{array}$} & \multirow{2}{*}{$\begin{array}{l}\text { Reference } \\
\text { Stenvers projection }\end{array}$} \\
\hline & HRCT & $\mathrm{CBCT}$ & HRCT & $\mathrm{CBCT}$ & HRCT & $\mathrm{CBCT}$ & \\
\hline Mean CDL (mm) & 35.5 & 37.0 & 36.0 & 38.2 & 37.0 & 37.6 & 43.2 \\
\hline SD CDL (mm) & 1.4 & 1.3 & 1.2 & 2.0 & 1.8 & 1.7 & 4.3 \\
\hline Mean CC (\%) & 89.0 & 85.2 & 87.7 & 82.7 & 85.3 & 83.9 & 74 \\
\hline $\operatorname{SD~CC~}(\%)$ & 3.6 & 3.0 & 2.8 & 4.2 & 4.2 & 3.8 & 7.4 \\
\hline Mean AI $\left(^{\circ}\right)$ & 800.8 & 766.6 & 789.4 & 744.5 & 767.8 & 755.5 & 663.3 \\
\hline $\operatorname{SD~IA~}\left(^{\circ}\right)$ & 32.6 & 26.9 & 25.3 & 37.9 & 37.3 & 34.1 & 65.4 \\
\hline
\end{tabular}


Fig. 2 Scatterplot showing the distribution of values of CDL estimation of the individual techniques and the $\mathrm{CDL}_{\text {reference. }}$ a Significant differences between the reference and every other method were found. Furthermore, significant differences between the A-value method obtained from $\mathrm{CBCT}$ and HRCT as well as between the A-value method obtained from $\mathrm{CBCT}$ and the $3 \mathrm{D}$ segmentation-based method obtained from HRCT were found. $\mathbf{b}$ Scatterplot after omitting correction factor. All measurement values approach to those from the reference. Asterisks mark $p$ value of differences of the individual approaches compared to the reference. $* * * p<0.001 ; * p<0.05$; n.s., not significant. Boxes indicate mean values. Whiskers indicate standard deviation
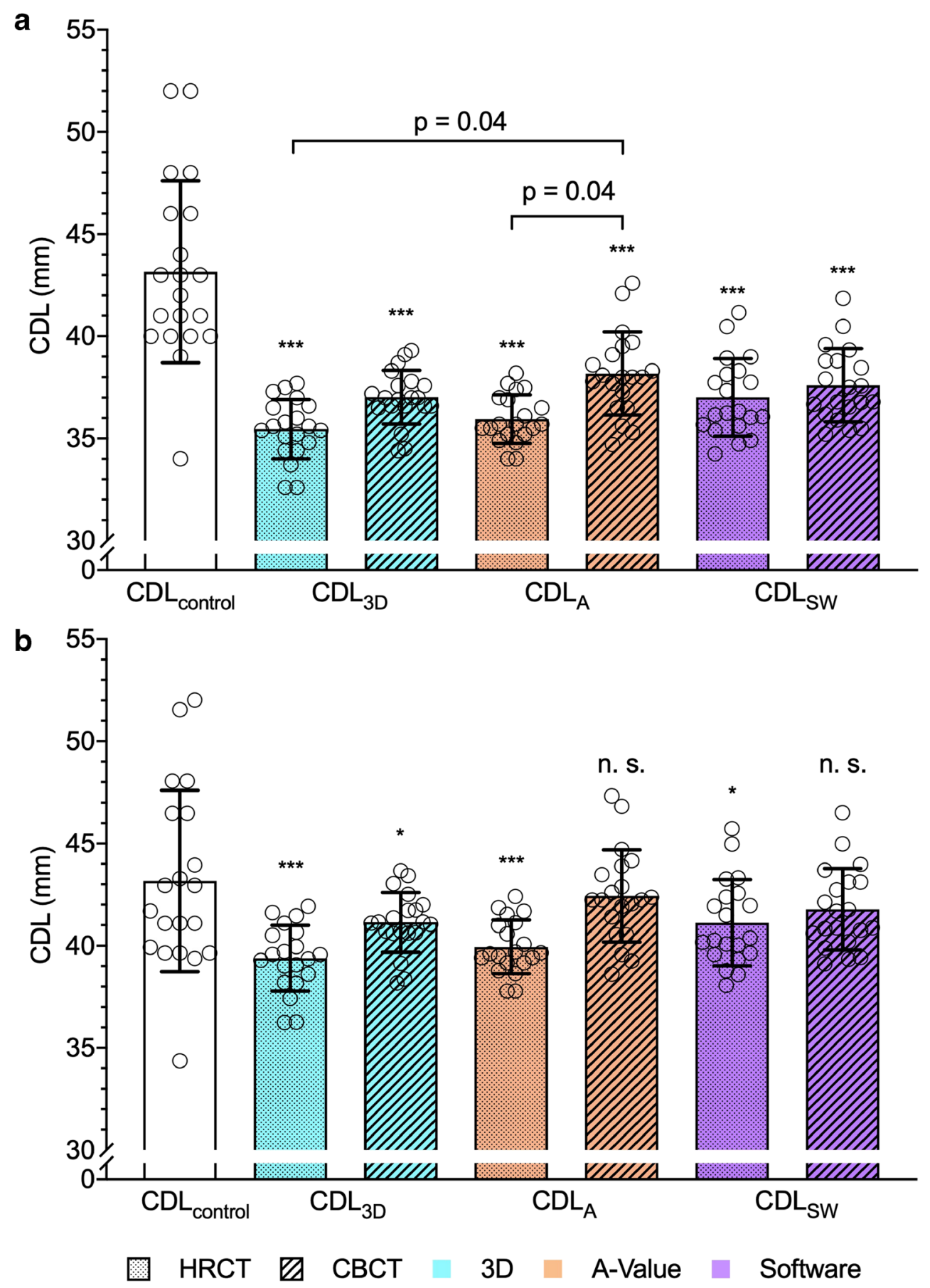

$0.78(p<0.001)$, between the B-value and the CDL $0.95(p<$ $0.001)$, and between the H-value and the CDL $0.70(p=$ 0.0007). Measured by CBCT, PCC between the A-value and the CDL was $0.87(p<0.001)$, between the B-value and the CDL $0.97(p<0.001)$, and between the H-value and the CDL $0.80(p<0.001)$.

The inter-rater reliability among investigators was assessed using the ICC. The results are shown in Table 2. A fair interrater reliability for the $\mathrm{CDL}_{3 \mathrm{D}-\mathrm{CBCT}}$, a good inter-rater reliability for the $\mathrm{CDL}_{3 \mathrm{D}-\mathrm{HRCT}}$, a poor inter-rater reliability for the
$\mathrm{CDL}_{\mathrm{A}-\mathrm{HRCT}}$, and an excellent inter-rater reliability per [29] for $\mathrm{CDL}_{\mathrm{A}-\mathrm{CBCT}}$, for $\mathrm{CDL}_{\mathrm{SW}-\mathrm{HRCT}}$, for $\mathrm{CDL}_{\mathrm{SW}-\mathrm{CBCT}}$, and for $\mathrm{CDL}_{\text {reference }}$ were found.

\section{Discussion}

The aim of this study was to investigate the accuracy and reliability of CDL measurements applied in clinical routine imaging. 3D segmentation was (i) intuitive and feasible even 

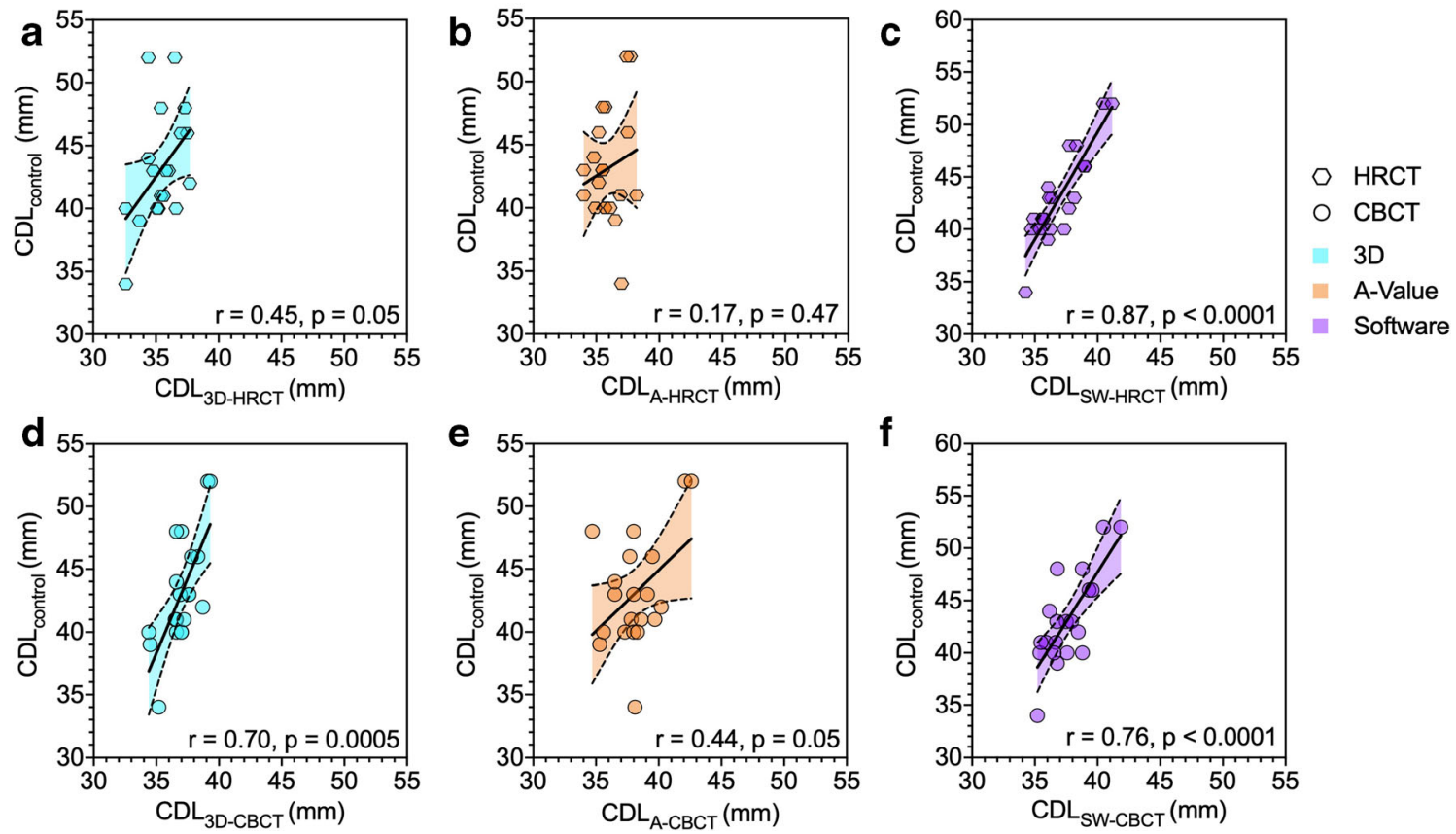

Fig. 3 Correlations between the individual approaches and the reference. a-c Estimations obtained from HRCT using the 3D segmentation-based method (a), A-value-based method (b), and software-based method (c). d-f Estimations obtained from $\mathrm{CBCT}$ using the 3D segmentation-based method (d), A-value-based method (e), and software-based method (f). r, Pearson's correlation coefficient. Line represents linear regression line. Dashed lines represent $95 \%$ prediction interval for less experienced users and (ii) the anatomical orientation is supported by the possibility to rotate the cochlea. This enables a full view onto the basal turn of the cochlea to apply the Avalue method. 3D reconstruction complements conventional tomography and provides information about anatomical particularities that may influence the electrode choice [14, 28]. These information have usually been gained by histological examinations post mortem [30]. However, in the present study, the correlations of $\mathrm{CDL}_{3 \mathrm{D}}$ to the $\mathrm{CDL}_{\text {reference }}$ were only moderate and the inter-rater reliability varied between fair to good depending on the imaging modality. Inter-rater differences may be explained by the alignment of the cochlea in the coordinate system. Further disadvantages are its time effort and the need for reconstruction of cochlear fluid spaces. The HU threshold ranges need to be set manually, which may lead to inaccuracies especially when considering that $\mathrm{CBCT}$ and HRCT are not primarily used to assess soft tissue and fluids. Summarizing these observations, the method is considered prone to errors and has a flat learning curve.
The A-value method exhibited the poorest correlation with the $\mathrm{CDL}_{\text {reference. }}$ Even though the method showed a high interrater reliability, only the basal turn is taken into account which leaves unattended the variability in the cochlear shape [7] and has a poorer correlation with the CDL compared to the Bvalue. This is in line with another experimental study demonstrating a significant underestimation of CDL from the Avalue method compared to synchrotron imaging [31].

The otosurgical planning software-based method was considered intuitive and is the only presented method that is authorized for clinical use. Clinical standard imaging data may be used for the analysis. The required reformation to an oblique coronal view may be a barrier to obtaining accurate basal turn parameters as also remarked by Guenette [32]. Smaller differences in the imaging quality and the basal turn orientation may disproportionately influence final measurements. However, the method showed the highest correlations to the reference values and the best inter-rater reliability. This is in line with the findings of Canfarotta et al who reported an
Table 2 Inter-rater reliability for the different measurement techniques. ICC, intra-class correlation coefficient; $I C C_{A}$, intraclass correlation coefficient Avalue; $I C C_{B}$, intra-class correlation coefficient $\mathrm{B}$-value

\begin{tabular}{llllllll}
\hline & $\begin{array}{l}\mathrm{CDL}_{3 \mathrm{D}-} \\
\mathrm{HRCT}\end{array}$ & $\begin{array}{l}\mathrm{CDL}_{3 \mathrm{D}-} \\
\mathrm{CBCT}\end{array}$ & $\begin{array}{l}\mathrm{CDL}_{\mathrm{A}-} \\
\mathrm{HRCT}\end{array}$ & $\begin{array}{l}\mathrm{CDL}_{\mathrm{A}-} \\
\mathrm{CBCT}\end{array}$ & $\begin{array}{l}\mathrm{CDL}_{\mathrm{SW}-} \\
\mathrm{HRCT}\end{array}$ & $\begin{array}{l}\mathrm{CDL}_{\mathrm{SW}-} \\
\mathrm{CBCT}\end{array}$ & $\mathrm{CDL}_{\text {reference }}$ \\
\hline $\mathrm{ICC}$ & 0.71 & 0.43 & 0.29 & 0.87 & 0.94 & 0.94 & 0.87 \\
$\mathrm{ICC}_{\mathrm{A}}$ & - & - & 0.28 & 0.87 & 0.86 & 0.89 & - \\
$\mathrm{ICC}_{\mathrm{B}}$ & - & - & - & - & 0.93 & 0.87 & - \\
\hline
\end{tabular}


excellent agreement in the determination of the CDL [33]. The software uses a correction factor of 0.9 that is calculated to reduce the CDL from the LW size to the estimated size of the organ of Corti [27]. This factor is higher than the one suggested by Kawano et al [34] but may still lead to an underestimation of the CDL. Schurzig et al found CDL values approximately $10 \%$ larger, when segmented from highresolution $\mu \mathrm{CT}$ images. It was concluded that the points placed onto the cochlear LW within CBCT images are located too close to the modiolus, resulting in a shorter estimated CDL [23]. This supports the findings of the current study where an underestimation of the CDL was observed. However, when applying an addition of $10 \%$, the values approached the $\mathrm{CDL}_{\text {reference }}$ (Fig. 2B).

With a CDL range between 35.5 and $43.1 \mathrm{~mm}$, the overall CDL range is in accordance to the values reported in the literature [24, 35]. However, only few studies considered the influence of imaging quality and resolution by applying the methods in different imaging modalities and lack a comparison of methods that are not authorized for clinical application to a clinically approved otosurgical planning software [22, 36]. Summarizing these results, a gold standard for the determination of the CDL is still missing.

This study showed the best correlations between $\mathrm{CDL}_{\mathrm{SW}}$ HRCT and $\mathrm{CDL}_{\text {reference. }}$. Furthermore, this method is supported by an excellent inter-rater reliability. Overall CBCT measurements showed higher correlations to the $\mathrm{CDL}_{\text {reference. This }}$ may be explained by the CBCT protocol used with a higher resolution and lower slice thickness than HRCT. Furthermore, the value of CBCT in CDL estimation is supported by Schurzig et al who found high correlation rates between CDL estimated by CBCT and $\mu \mathrm{CT}$. Identifying the $\mathrm{LW}$ was easier in the basal region, but becomes more difficult in the middle and apical turn [37]. These findings highlight the importance of image resolution and may explain weaker correlations between the CDL and the cochlear height compared to the A-value and B-value. In this study, the width of the cochlea (B-value) had a larger influence on the CDL than the Avalue. This is in line with another study describing a stronger correlation between the CDL and the B-value $(r=0.96)$ compared to the A-value $(r=0.63)$ [38]. A recent study by Oh et al showed correlations between the A-value and the IA comparable to this study but higher correlations between the A-value and the postoperative IA compared to the B-value [39]. These results may be explained by the lower IA with a mean of only $440^{\circ}[32,39]$. Consequently, the determination of the basal turn length may be useful and leads to more accurate IA predictions when a shorter electrode is chosen. However, the impact of cochlear height and the radius of middle and apical turn may increase with a deeper electrode insertion or anatomical variations.

From the results of this study, the otosurgical planning software-based method is recommended for determining
CDL in a normal shaped cochlea. However, this method only takes into account the A-value and B-value to determine the CDL. The H-value is not respected by the formula, even though a high correlation between $\mathrm{H}$-value and $\mathrm{CDL}_{\mathrm{Sw}}$ was shown in this study. Regarding these findings, the accuracy of the software-based CDL measurement is likely to depend on a normal shaped basal turn and may consequently limit the use of the otosurgical planning software for the electrode choice in cases of inner ear malformation (IEM).

Concerning the imaging modality, we found the best agreement between the $\mathrm{CDL}_{\text {reference }}$ and $\mathrm{CDL}$ values obtained from HRCT. However, in clinical application, the decision whether to use CBCT or HRCT may additionally depend on other factors such as the patient age and radiohygiene. The CBCT has an optimum in combination of spatial resolution and radiation exposure for skull base examinations in the high-contrast range. However, CBCT is associated with a 2 to 3 times higher eye dose during temporal bone examinations [40]. Since the correlations between the $\mathrm{CDL}_{\text {reference }}$ and the $\mathrm{CDL}_{\mathrm{SW} \text {-HRCT }}$ and between the $\mathrm{CDL}_{\text {reference }}$ and the $\mathrm{CDL}_{\mathrm{SW} \text { - }}$ $\mathrm{CBCT}$ were not significantly different, the modality should be chosen in consensus with the neuroradiologist within the center.

This study is limited by a comparatively small number of temporal bones. Reproducibility of the results should be evaluated in larger prospective clinical trials. However, a number of 20 temporal bones is higher compared to other experimental studies using human temporal bone specimens [23, 41]. Varying estimated CDL may result from poor imaging resolution, insufficient referencing, and inadequate mathematical cochlea modelling. Small variances in the electrode position after implantation (LW versus perimodiolar) may lead to different values and estimation errors. Yet, $\mathrm{CDL}_{\text {reference }}$ obtained from Stenvers projection was considered to be the closest approximation to the clinical application of CDL estimations since it predicts the electrode position. Furthermore, MED-EL Flex soft electrodes are the thickest available electrodes and consequently are considered to exhibit the fewest variation inside the cochlear duct.

\section{Conclusion}

Different values for the CDL depending on the imaging modality and the imaging processing software were observed. These variations may result from inaccuracies of the applied approaches and the mathematical CDL modelling. Further explanations are measurement errors or insufficient imaging resolution. Overall, the CDL was underestimated by each of the applied methods. As a consequence, all measurements would presumably have led to an electrode choice of rather too short electrodes. Particularly, in cases of electric acoustic stimulation where a precise electrode choice according to the 
residual hearing is desirable, these findings are of importance. Concerning treatment decisions based on CDL measurements, a method considering both A-value and B-value that is approved for clinical use has to be recommended for patients with a normal cochlea shape. Furthermore, we provide evidence that any correction factor may be omitted. All present models for CDL estimation appear not to achieve the level of precision needed for an appropriate estimation of pitch match or $\mathrm{CC}$ in residual hearing by electrode selection.

Funding information Open Access funding enabled and organized by Projekt DEAL. This study has received funding from the KIND hearing foundation.

\section{Declarations}

Guarantor The scientific guarantor of this publication is Nora M. Weiss.

Conflict of interest The authors of this manuscript declare relationships with the following companies: Author AD is employed at MED-EL $\mathrm{GmbH}$ as the Head of Translational Science Communication, which is purely a scientific role with no marketing activities. The other authors of this manuscript declare no relationships with any companies, whose products or services may be related to the subject matter of the article.

Statistics and biometry No complex statistical methods were necessary for this paper.

Informed consent Written informed consent was obtained from all subjects (patients) in this study.

Ethical approval Institutional Review Board approval was obtained.

\section{Methodology \\ - Experimental \\ - Performed at one institution}

Open Access This article is licensed under a Creative Commons Attribution 4.0 International License, which permits use, sharing, adaptation, distribution and reproduction in any medium or format, as long as you give appropriate credit to the original author(s) and the source, provide a link to the Creative Commons licence, and indicate if changes were made. The images or other third party material in this article are included in the article's Creative Commons licence, unless indicated otherwise in a credit line to the material. If material is not included in the article's Creative Commons licence and your intended use is not permitted by statutory regulation or exceeds the permitted use, you will need to obtain permission directly from the copyright holder. To view a copy of this licence, visit http://creativecommons.org/licenses/by/4.0/.

\section{References}

1. Vermeire K, Nobbe A, Schleich P, Nopp P, Voormolen MH, Van de Heyning PH (2008) Neural tonotopy in cochlear implants: an evaluation in unilateral cochlear implant patients with unilateral deafness and tinnitus. Hear Res 245(1-2):98-106. https://doi.org/ 10.1016/j.heares.2008.09.003

2. Buchner A, Illg A, Majdani O, Lenarz T (2017) Investigation of the effect of cochlear implant electrode length on speech comprehension in quiet and noise compared with the results with users of electro-acoustic-stimulation, a retrospective analysis. PLoS One 12(5):e0174900. https://doi.org/10.1371/journal.pone.0174900

3. Stakhovskaya O, Sridhar D, Bonham BH, Leake PA (2007) Frequency map for the human cochlear spiral ganglion: implications for cochlear implants. J Assoc Res Otolaryngol 8(2):220-233. https://doi.org/10.1007/s10162-007-0076-9

4. Timm ME, Majdani O, Weller T et al (2018) Patient specific selection of lateral wall cochlear implant electrodes based on anatomical indication ranges. PLoS One 13(10):e0206435. https://doi.org/10. 1371/journal.pone.0206435

5. Xu J, Xu SA, Cohen LT, Clark GM (2000) Cochlear view: postoperative radiography for cochlear implantation. Am J Otol 21(1):4956

6. Dimopoulos P, Muren C (1990) Anatomic variations of the cochlea and relations to other temporal bone structures. Acta Radiol 31(5): 439-444

7. Rask-Andersen H, Erixon E, Kinnefors A, Lowenheim H, SchrottFischer A, Liu W (2011) Anatomy of the human cochleaimplications for cochlear implantation. Cochlear Implants Int 12(Supp1 1):S 8-S13. https://doi.org/10.1179/ $146701011 X 13001035752174$

8. Avci E, Nauwelaers T, Lenarz T, Hamacher V, Kral A (2014) Variations in microanatomy of the human cochlea. J Comp Neurol 522(14):3245-3261. https://doi.org/10.1002/cne.23594

9. Wysocki J (1999) Dimensions of the human vestibular and tympanic scalae. Hear Res 135(1-2):39-46. https://doi.org/10.1016/ s0378-5955(99)00088-x

10. Biedron S, Prescher A, Ilgner J, Westhofen M (2010) The internal dimensions of the cochlear scalae with special reference to cochlear electrode insertion trauma. Otol Neurotol 31(5):731-737. https:// doi.org/10.1097/MAO.0b013e3181d27b5e

11. Escude B, James C, Deguine O, Cochard N, Eter E, Fraysse B (2006) The size of the cochlea and predictions of insertion depth angles for cochlear implant electrodes. Audiol Neurootol 11(Suppl 1):27-33. https://doi.org/10.1159/000095611

12. Shin K-J, Lee J-Y, Kim J-N et al (2013) Quantitative analysis of the cochlea using three-dimensional reconstruction based on microcomputed tomographic images. Anat Rec (Hoboken) 296(7):1083-1088. https://doi.org/10.1002/ar.22714

13. Verbist BM, Ferrarini L, Briaire JJ et al (2009) Anatomic considerations of cochlear morphology and its implications for insertion trauma in cochlear implant surgery. Otol Neurotol 30(4):471-477. https://doi.org/10.1097/MAO.0b013e3181a32c0d

14. Weiss NM, Langner S, Mlynski R, Roland P, Dhanasingh A (2021) Evaluating common cavity cochlear deformities using CT images and 3D reconstruction. Laryngoscope 131(2):386-7391. https:// doi.org/10.1002/lary.28640

15. Weller T, Timm M, Büchner A, Lenarz T (2019) Individualisierte CI-Versorgung: Welchen Einfluss hat die Wahl des Elektrodenträgers?, 21. Jahrestagung der Deutschen Gesellschaft für Audiologie, Heidelberg, Germany (scientific report)

16. Doubi A, Almuhawas F, Alzhrani F, Doubi M, Aljutaili H, Hagr A (2019) The effect of cochlear coverage on auditory and speech performance in cochlear implant patients. Otol Neurotol 40(5): 602-607. https://doi.org/10.1097/MAO.0000000000002192

17. Mlynski R, Lüsebrink A, Oberhoffner T, Langner S, Weiss NM (2021) Mapping cochlear duct length to electrically evoked compound action potentials in cochlear implantation. Otol Neurotol 42(3):e254-7e260. https://doi.org/10.1097/MAO. 0000000000002957 
18. Skinner MW, Ketten DR, Holden LK et al (2002) CT-derived estimation of cochlear morphology and electrode array position in relation to word recognition in Nucleus-22 recipients. J Assoc Res Otolaryngol 3(3):332-350. https://doi.org/10.1007/ s101620020013

19. Weiss NM, Dhanasingh A, Schraven SP, Schulze M, Langner S, Mlynski R (2019) Surgical approach for complete cochlear coverage in EAS-patients after residual hearing loss. PLoS One 14(9): e0223121. https://doi.org/10.1371/journal.pone.0223121

20. Gaskell P, Muzaffar J, Colley S, Coulson C (2018) Can preoperative high resolution computed tomography be rationalized in adult cochlear implant candidates? Otol Neurotol 39(10):1264-1270. https://doi.org/10.1097/MAO.0000000000002027

21. Dhanasingh A, Jolly C (2017) An overview of cochlear implant electrode array designs. Hear Res 356:93-103. https://doi.org/10. 1016/j.heares.2017.10.005

22. Nateghifard K, Low D, Awofala L et al (2019) Cone beam CT for perioperative imaging in hearing preservation Cochlear implantation - a human cadaveric study. J Otolaryngol Head Neck Surg 48(1):65. https://doi.org/10.1186/s40463-019-0388-x

23. Schurzig D, Timm ME, Lexow GJ, Majdani O, Lenarz T, Rau TS (2018) Cochlear helix and duct length identification - evaluation of different curve fitting techniques. Cochlear Implants Int 19(5):268283. https://doi.org/10.1080/14670100.2018.1460025

24. Würfel W, Lanfermann H, Lenarz T, Majdani O (2014) Cochlear length determination using cone beam computed tomography in a clinical setting. Hear Res 316:65-72. https://doi.org/10.1016/j. heares.2014.07.013

25. Kuthubutheen J, Grewal A, Symons S et al (2019) The effect of cochlear size on cochlear implantation outcomes. Biomed Res Int 2019:5849871. https://doi.org/10.1155/2019/5849871

26. Li H, Schart-Morén N, Rohani SA, Ladak HM, Rask-Andersen H, Agrawal S (2020) Synchrotron radiation-based reconstruction of the human spiral ganglion: implications for cochlear implantation. Ear Hear 41(1):173-181. https://doi.org/10.1097/AUD. 0000000000000738

27. Dhanasingh A (2019) Cochlear duct length along the outer wall vs organ of Corti: which one is relevant for the electrode array length selection and frequency mapping using Greenwood function? World J Otorhinolaryngol Head Neck Surg 5(2):117-121. https:// doi.org/10.1016/j.wjorl.2018.09.004

28. Sieber D, Erfurt P, John S et al (2019) The OpenEar library of 3D models of the human temporal bone based on computed tomography and micro-slicing. Sci Data 6:180297. https://doi.org/10.1038/ sdata.2018.297

29. Cicchetti D (1994) Guidelines, criteria, and rules of thumb for evaluating normed and standardized assessment instrument in psychology. Psychol Assess 6:284-290. https://doi.org/10.1037/10403590.6.4.284

30. Erixon E, Hogstorp H, Wadin K, Rask-Andersen H (2009) Variational anatomy of the human cochlea: implications for cochlear implantation. Otol Neurotol 30(1):14-22. https://doi.org/ 10.1097/MAO.0b013e31818a08e8

31. Koch RW, Elfarnawany M, Zhu N, Ladak HM, Agrawal SK (2017) Evaluation of cochlear duct length computations using synchrotron radiation phase-contrast imaging. Otol Neurotol 38(6):e92-e99. https://doi.org/10.1097/MAO.0000000000001410

32. Guenette JP (2021) Measuring the cochlea and cochlear implant electrode depth. Eur Radiol 31(3):1257-1259. https://doi.org/10. 1007/s00330-020-07602-1

33. Canfarotta MW, Dillon MT, Buss E, Pillsbury HC, Brown KD, O'Connell BP (2019) Validating a new tablet-based tool in the determination of cochlear implant angular insertion depth. Otol Neurotol 40(8):1006-1010. https://doi.org/10.1097/MAO. 0000000000002296

34. Kawano A, Seldon HL, Clark GM (1996) Computer-aided threedimensional reconstruction in human cochlear maps: measurement of the lengths of organ of Corti, outer wall, inner wall, and Rosenthal's canal. Ann Otol Rhinol Laryngol 105(9):701-709. https://doi.org/10.1177/000348949610500906

35. Koch RW, Ladak HM, Elfarnawany M, Agrawal SK (2017) Measuring cochlear duct length - a historical analysis of methods and results. J Otolaryngol Head Neck Surg 46(1):19. https://doi. org/10.1186/s40463-017-0194-2

36. Gee AH, Zhao Y, Treece GM, Bance ML (2021) Practicable assessment of cochlear size and shape from clinical CT images. Sci Rep 11(1):3448. https://doi.org/10.1038/s41598-021-83059-6

37. Schurzig D, Timm ME, Batsoulis C et al (2018) A novel method for clinical cochlear duct length estimation toward patient-specific cochlear implant selection. OTO Open 2(4):2473974X18800238. https://doi.org/10.1177/2473974X18800238

38. Khurayzi T, Almuhawas F, Sanosi A (2020) Direct measurement of cochlear parameters for automatic calculation of the cochlear duct length. Ann Saudi Med 40(3):212-218. https://doi.org/10.5144/ 0256-4947.2020.218

39. Oh J, Cheon J-E, Park J et al (2021) Cochlear duct length and cochlear distance on preoperative CT: imaging markers for estimating insertion depth angle of cochlear implant electrode. Eur Radiol 31(3):1260-1267. https://doi.org/10.1007/s00330-020-07580-4

40. Knörgen M, Brandt S, Kösling S (2012) Comparison of quality on digital X-ray devices with 3D-capability for ENT-clinical objectives in imaging of temporal bone and paranasal sinuses. Rofo. 184(12):1153-1160. https://doi.org/10.1055/s-0032-1325343

41. Schurzig D, Lexow GJ, Majdani O, Lenarz T, Rau TS (2016) Three-dimensional modeling of the cochlea by use of an arc fitting approach. Comput Methods Biomech Biomed Engin 19(16):17851799. https://doi.org/10.1080/10255842.2016.1188921

Publisher's note Springer Nature remains neutral with regard to jurisdictional claims in published maps and institutional affiliations. 